\title{
Starvation-Induced Genes of the Tomato Pathogen Cladosporium fulvum Are Also Induced During Growth In Planta
}

\author{
Mark Coleman, Beatrice Henricot, Jose Arnau, and Richard P. Oliver \\ Norwich Molecular Plant Pathology Group, School of Biological Sciences, University of East Anglia, Norwich \\ NR4 7TJ, U.K. \\ Accepted 5 September 1997.
}

\begin{abstract}
The pathogenicity of fungal pathogens is presumably dependent on genes that are expressed during infection. In order to isolate such genes from the tomato pathogen $\mathrm{Cla}$ dosporium fulvum, and to test the hypothesis that starvation-induced genes are also plant induced, a cDNA library was prepared from mycelia grown in a defined medium and then transferred to a starvation medium. The library was then screened with cDNA probes prepared from starved and replete fungal mycelium. Five unique, differentially expressed cDNAs were isolated from 1,000 clones screened. Northern (RNA) hybridization confirmed that all five were starvation induced. Interestingly, all five were also found to be plant induced. The identity of two of the clones was indicated by partial DNA sequencing as alcohol and aldehyde dehydrogenase. The observed correlation between starvation induction and plant induction is discussed.
\end{abstract}

Fungal phytopathogenicity is presumed to be dependent upon pathogen factors required for penetration, survival, symptom development, and growth within the plant host. Progress in isolating and characterizing genes required for pathogenicity has been reviewed (Oliver and Osbourn 1995; VanEtten et al. 1995; Bhattacharyya et al. 1997). Many groups have taken a direct approach to clone genes whose products were suspected to be required for disease development. Such genes include those encoding cell wall-degrading enzymes, enzymes degrading preformed or induced anti-fungal toxins and phytotoxin synthesis. In order to identify genes involved in novel or unsuspected steps in the infection process, other groups have used "black box" approaches such as the analysis of differential gene or protein expression and random mutagenesis. In the former case, genes induced by growth in

Corresponding author: Richard P. Oliver; Fax: +45 3327 4766; E-mail: rpo@crc.dk

Present address of Beatrice Henricot and Richard P. Oliver: Physiology Department, Carlsberg Laboratory, Gamle Carlsberg Vej 10, Copenhagen, DK-2500, Denmark.

Present address of Jose Arnau: Biotechnology Institute, Kogle Alle 2, Horsholm, DK-2970, Denmark. the plant (Pieterse et al. 1993a, 1993b; Talbot et al. 1993; Benito et al. 1996), specific to developmental stages (Hwang and Kolattukudy 1995; Justesen et al. 1996) or proteins only found in infected tissue (Honee et al. 1994; Marmeisse et al. 1994) have been isolated. In the latter case, mutants deficient in pathogenicity were isolated by, for example, a restriction enzyme-mediated integration method (Bölker et al. 1995). Direct proof of involvement in pathogenicity of the genes identified above has only been obtained in a handful of cases.

This paucity of direct evidence about the nature of pathogenicity determinants demands that new approaches be developed and tested. The isolation of pathogen genes expressed specifically during infection of the host plant has provided an alternative to predictive approaches for the identification of pathogenicity determinants. Differential screening of a Phytophthora infestans genomic DNA library with cDNA from infected plants and from in vitro-grown fungus identified nine genes that exhibited in planta-induced expression (Pieterse et al. 1991, 1993a, 1993b, 1994a, 1994b). The identity of many of these genes and their requirement for pathogenicity are at present unclear. The MPGI gene of Magnaporthe grisea was isolated by the differential screening of a cDNA library constructed from $M$. grisea-infected rice leaves. Presumed to encode a hydrophobin, its disruption resulted in a significant reduction in virulence (Talbot et al. 1993). With a differential display reverse transcriptase-polymerase chain reaction method, five Botrytis cinerea cDNAs were isolated but no homology was found with any known genes (Benito et al. 1996).

We are interested in identifying pathogenicity determinants of Cladosporium fulvum Cooke (syn. Fulvia fulva (Cooke) Cif.) a non-obligate biotrophic pathogen of tomato (Lycopersicon esculentum Mill.). We noticed that a number of fungal pathogen genes that exhibit in planta-induced expression have been shown to be also expressed in vitro under conditions of nutrient deprivation. Thus, the avr9 gene of $C$. fulvum, which encodes an elicitor of host defense, exhibits in vitro expression only in response to acute nitrogen deprivation (van den Ackerveken et al. 1994). The in planta-induced genes $i p i B$ and $i p i O$ from $P$. infestans also exhibit greatly enhanced expression in vitro in response to nutrient deprivation; for $i p i B$, carbon deprivation is sufficient to cause induction 
(Pieterse et al. 1994a). Similarly, M. grisea MPGI expression is induced in vitro in response to nutrient deprivation (Talbot et al. 1993). More recently, a search for genes that would impair nitrogen metabolism identified two genes, NPRI and $N P R 2$, that are essential for MPG1 expression and hence pathogenicity (Lau and Hamer 1996).

We set out to test the hypothesis that a significant proportion of in vitro starvation-induced genes of $C$. fulvum would also be plant induced. In the current study, we have isolated five cDNAs of $C$. fulvum genes that exhibit expression induced under conditions of carbon and nitrogen deprivation. Analysis of the expression of these genes during tomato infection showed that all five also exhibited induced expression in planta. Starvation may thus represent at least a component of the signal for the expression of genes required for growth on the host and the isolation of starvation-induced genes may provide a rapid means of identifying putative fungal pathogenicity determinants.

A cDNA library prepared in $\lambda$ ZAPII (Stratagene, La Jolla, CA) from $C$. fulvum transferred to B5-NC was screened to select clones representing starvation-induced genes. The screening of approximately 1,000 plaques identified 10 clones that appeared to hybridize more strongly to the cDNA probe prepared from starved $C$. fulvum. These $10 \mathrm{cDNA}$ clones were excised from $\lambda$ ZAPII to yield plasmid clones, designated pSI1 to pSI-10. DNA preparations of each were examined by a combination of restriction digestion, cross-hybridization, and partial sequencing to reveal which clones were unique. The clone $p S I-4$ was found to be a short version of pSI-5 and pSI10 was identical to pSI-2, 3, 6 , and 8 . This left five unique, putatively differentially expressed clones.

The differentially hybridizing cDNA clones pSI-1, pSI-5, pSI-7, pSI-9, and pSI-10 were used to probe Northern (RNA) blots containing (i) approximately equal quantities of poly $\mathrm{A}^{+}$ RNA isolated from $C$. fulvum grown under starvation and control conditions, and (ii) approximately equal quantities of total RNA isolated from tomato leaves harvested 8 or 14 days post C. fulvum inoculation and harvested from uninfected plants (Fig. 1). C. fulvum actin, which is presumed to be constitutively expressed, was used as a control. The hybridization patterns obtained confirmed that all five cDNA clones represented genes that exhibited starvation-induced expression (Fig. 1, lanes 1 vs. 2). Importantly, all five of the genes also appeared to be induced during pathogenesis, in that the hybridization to infected plant RNA (Fig. 1, lane 4) exceeded the hybridization to RNA from control, in vitro-grown mycelium (Fig. 1, lane 1). RNA from uninfected tomato plants hybridized to none of the probes (Fig. 1, lane 5).

To assess quantitatively the degree of induction of gene expression during starvation and growth in planta, phosphoimage analysis (Fuji BAS1000 IP) was used to quantitate the intensity of Northern blot hybridization signals. The fold induction under different conditions (relative to the fully fed mycelium) is shown in Table 1 . These data clearly demonstrate that all of the identified starvation-induced cDNA clones represent genes expressed in planta and the level of in planta gene expression is very much greater than that exhibited during growth in full minimal medium. The genes fall broadly into two classes: one class whose expression in planta is relatively less than in vitro starvation conditions (pSI-9, pSI-10), and one class represented by pSI-1, pSI-5, and pSI-7, for which there is a striking similarity between the degree of induction upon starvation and during growth upon tomato. Four of the clones (pSI-1, 7, 9, and 10) were essentially full length. There was a 300-fold range in the absolute signal intensities of the different clones following hybridization to RNA of starved mycelium, indicating the technique can identify weakly expressed genes.

Terminal DNA sequences obtained with vector primers were compared with the Owl data bases, using BLASTX (Altschul et al. 1990). Such analysis revealed a clear homology between the sequences of two of the clones and known

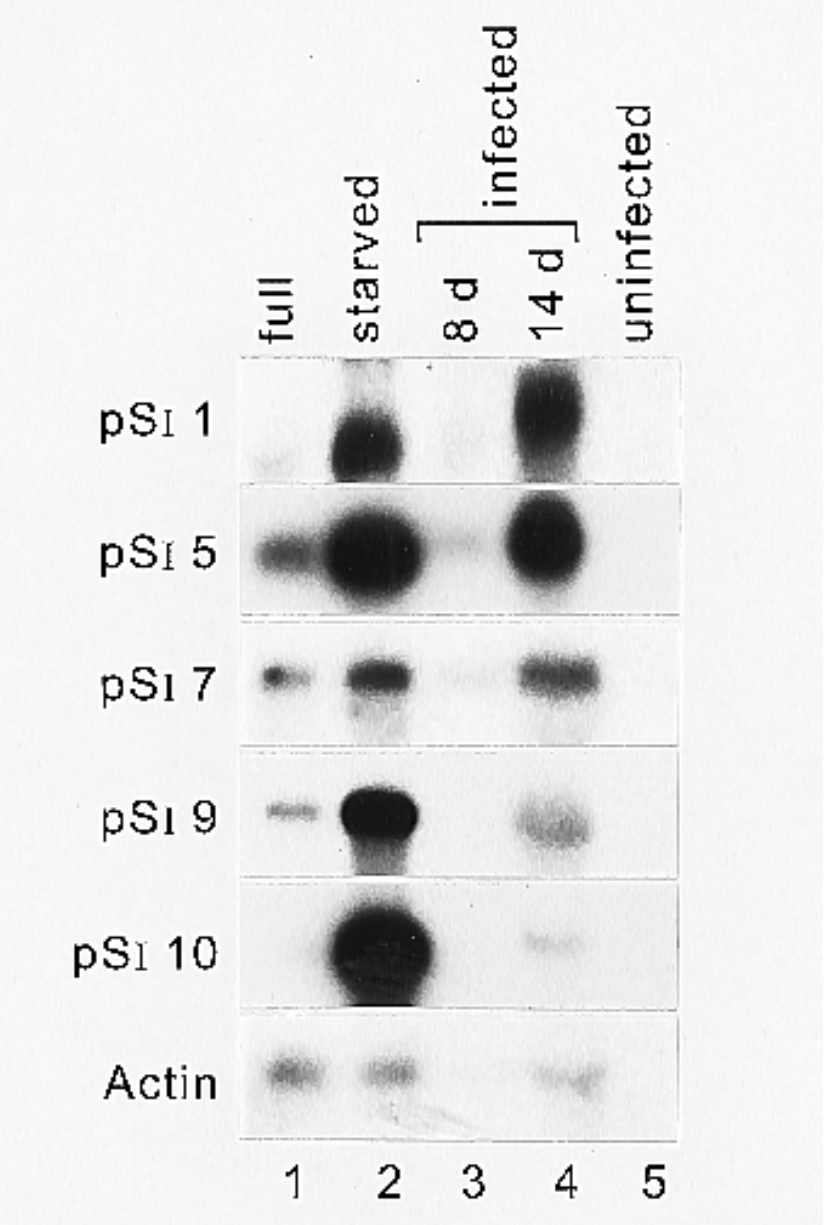

Fig. 1. Hybridization of pSI clones to polyA ${ }^{+}$RNA from fully fed Cladosporium fulvum (lane 1), starved C. fulvum (lane 2), or total RNA 8 (lane 3) or 14 (lane 4) days tomato post-infection and (lane 5) uninfected plants. C. fulvum race 4 was grown in liquid B5 medium (Gamborg et al. 1968 ) with shaking at $100 \mathrm{rpm}$ (Innova 2300, New Brunswick Scientific, Basingstoke, Hampshire, UK). Spores $\left(1 \times 10^{5}\right)$ prepared from 12-dayold, V8-grown $C$. fulvum were used to inoculate 250 -ml flasks containing $50 \mathrm{ml}$ of B5 medium. After $96 \mathrm{~h}$, the mycelium was filtered and washed with B5 medium containing no carbon or nitrogen source (B5$\mathrm{NC}$ ); the washed mycelium was immediately transferred to a $250-\mathrm{ml}$ flask containing $50 \mathrm{ml}$ of $\mathrm{B} 5-\mathrm{NC}$ and shaken as before. The mycelium was collected by filtration $16 \mathrm{~h}$ after transfer, frozen in liquid nitrogen, and lyophilized prior to RNA isolation. The above constituted the "starvation conditions." Fully fed $C$. fulvum race 4 was grown and treated in an identical manner except that the mycelium was washed and resuspended in fresh B5 medium. Total RNA was isolated from uninfected or infected tomato leaves (Dickinson et al. 1993). RNA was prepared as in Logemann et al. (1987). PolyA ${ }^{+}$RNA was prepared with Poly(A) Quick columns (Stratagene, La Jolla, CA). 
genes (Table 1 and Fig. 2). pSI-9 and pSI-10 show most homology to aldehyde dehydrogenase (EC 1.2.1.3) of $C$. herbarum and alcohol dehydrogenase (EC 1.1.1.1) of Aspergillus nidulans, respectively. Complete sequencing of pSI-1 and pSI5 has so far not revealed a convincing homology to any sequence in the data base. pSI-7 shows a strong homology to a yeast cDNA (YCR 68W; BLAST score 431) whose function is still unknown. However, hydrophobic domains present in the amino acid sequence suggest that it might be a membrane protein.

A significant proportion of the small group of fungal genes shown to be involved in pathogenicity is also induced during in vitro growth under starvation conditions (van den Ackerveken et al. 1994; Talbot et al. 1993). This observation invited the approach used in the current project; i.e., to use mRNA from starved, axenically grown mycelium as the source of the probe. The use of a cDNA library prepared from the same material obviates the need to subclone from a genomic library, makes it straightforward to establish the uniqueness of each clone by DNA sequencing, and gives direct access to the amino acid sequence of the putatively induced protein. It has the disadvantage that $5^{\prime}$ untranscribed regions are not readily identified.

The coincidence of starvation-induced clones with plantinduced clones is so far five out of five. This suggests that there is more than a coincidental link between the two induction conditions. It has long been noted that many, but not all, cell wall-degrading enzymes are catabolite repressed in plantpathogenic fungi (Cooper et al. 1988). As such, these genes would be starvation induced. The transcription of the pisatin demethylase gene in Nectria haematococca is repressed in rich media (Straney and VanEtten 1994). Also, there are a few reports that auxotrophic mutants of plant pathogens are nonpathogenic, implying that pathways for the biosynthesis of nucleotides and amino acids are induced during growth in the plant (Keitt and Boone 1954; Puhalla and Anagnostakis 1971; Marmeisse et al. 1993). A more generalized relationship between the nutritional environment of a host organism and the pathogenicity of parasites has been hypothesized (Garber 1956; Lewis 1953). The particular role of starvation in inducing gene expression required for pathogenicity is supported by recent evidence on the hypovirulence-inducing mycovirus of Cryphonectria parasitica (Choi et al. 1995; Larson et al. 1992; Larson and Nuss 1994). It appears that the hypovirulence-inducing mycovirus attenuates the starvation-induced transcription of genes correlated with pathogenicity, a process that appears to be G-protein mediated (Gao and Nuss 1996).
Evidence of a link between nitrogen metabolism and pathogenicity has been recently demonstrated in Magnaporthe grisea by Lau and Hamer (1996). They showed that nprl and $n p r 2$ mutants, deficient in various nitrogen source utilization, express low MPG1 mRNA levels during nitrogen and carbon starvation and consequently are defective in pathogenicity. These findings, added to those reported herein, suggest that a direct study of the starvation response will throw light on the pathogenic process (see also Marzluf 1997).

An advantage of screening a cDNA library is that the amino acid sequences of the putative protein products are immediately apparent from the DNA sequence. Thus, partial DNA sequencing of these clones has provided putative identities of two out of the five clones. The identification of alcohol and aldehyde dehydrogenase as plant-induced genes was unexpected. The significance of the connection between starvation, alcohol metabolism, and pathogenicity, if any, will require more information before it can be fully assessed. Most importantly, it remains to be seen whether disruption of any of

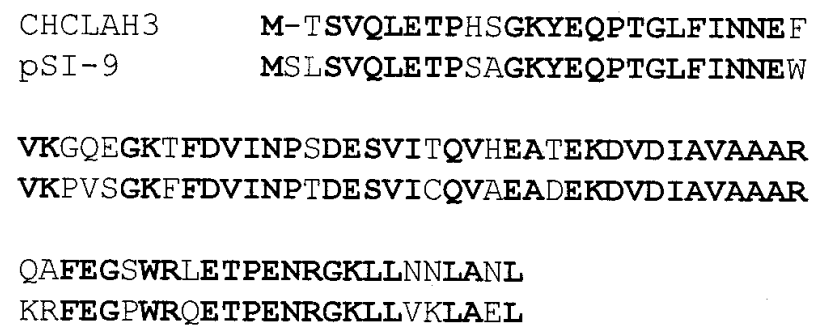

Fig. 2. Alignment of the pSI-9 open reading frame with the Cladosporium herbarum aldehyde dehydrogenase sequence (CHCLAH3) and of pSI-10 with the Aspergillus nidulans alcohol dehydrogenase gene (ADH1_EMENI).

Table 1. Characteristics of transcripts of starvation-induced clones

\begin{tabular}{|c|c|c|c|c|c|c|c|}
\hline \multirow[b]{2}{*}{ Clone name } & \multicolumn{2}{|c|}{ Transcript } & \multicolumn{2}{|c|}{ Infection (days) } & \multirow{2}{*}{$\begin{array}{c}\text { Transcript } \\
\text { size (bp) }\end{array}$} & \multirow{2}{*}{$\begin{array}{l}\text { Clone size } \\
\text { (bp) }\end{array}$} & \multirow{2}{*}{$\begin{array}{c}\text { Accession } \\
\text { no. }\end{array}$} \\
\hline & Starvation abundance $^{\mathrm{a}}$ & Starvation induction $^{\mathrm{b}}$ & $\mathbf{8}^{\mathrm{c}}$ & $14^{\mathrm{c}}$ & & & \\
\hline pSI-1 & 25 & 26 & 6 & 25 & 860 & 834 & Y14552 \\
\hline pSI-5 & 300 & 18 & 3 & 15 & 500 & 326 & Y14553 \\
\hline pSI-7 & 1 & 5 & $\mathrm{ND}^{\mathrm{d}}$ & 3.6 & 2,240 & 2,166 & Y14554 \\
\hline pSI-9 & 24 & 26 & 4 & 6 & 2,140 & 2,000 & Y14555 \\
\hline pSI-10 & 82 & 92 & 16 & 4 & 1,250 & 1,250 & Y14556 \\
\hline
\end{tabular}


the genes isolated above will have any significant effect on pathogenicity.

\section{ACKNOWLEDGMENTS}

This work was supported by the Carlsberg Foundation and by grants to R.P.O. from the Biotechnology and Biological Science Research Council (PO2461) and the European Union (CHRX-CT93-0244).

\section{LITERATURE CITED}

Altschul, S. F., Gish, W., Miller, W., Myers, E. W., and Lipman, D. J. 1990. Basic local alignment research tool. J. Mol. Biol. 215:403410.

Benito, E. P., Prins, T., and van Kan, J. A. L. 1996. Application of differential display RT-PCR to the analysis of gene expression in a plantfungus interaction. Plant Mol. Biol. 32:947-957.

Bhattacharyya, M., Bonas, U., Gelvin, S., Harrison, M., Huguet, E., Kanyuka, K., Kijne, J., Mas, J., Opperman, C., and Walton, J. 1997. IS-MPMI meeting report. Mol. Plant-Microbe Interact. 10:6-12.

Bölker, M., Böhnert, H. U., Braun, K. H., Görl, J., and Kahmann, R. 1995. Tagging pathogenicity genes in Ustilago maydis by restriction enzyme-mediated integration (REMI). Mol. Gen. Genet. 248:547-552.

Choi, G., Chen, B. S., and Nuss, D. L. 1995. Virus-mediated or transgenic suppression of a g-protein alpha-subunit and attenuation of fungal virulence. Proc. Natl. Acad. Sci. USA 92:305-309.

Cooper, R., Longman, D., Campbell, A., Henry, M., and Lees, P. 1988. Enzymatic adaptation of cereal pathogens to the monocotyledonous primary wall. Physiol. Mol. Plant Pathol. 32:33-47.

Dickinson, M. J., Jones, D. A., and Jones, J. D. G. 1993. Close linkage between the $C f-2 / C f-5$ and $M i$ resistance loci in tomato. Mol. PlantMicrobe Interact. 6:341-347.

Gamborg, O. L., Miller, R. A., and Ojima, K. 1968. Nutrient requirements of suspension cultures of soybean root cells. Exp. Cell Res. 50: 151-158.

Gao, S., and Nuss, D. L. 1996. Distinct roles for two G protein $\alpha$ subunits in fungal virulence, morphology, and reproduction revealed by targeted gene disruption. Proc. Natl. Acad. Sci. USA 93:1412214127.

Garber, E. 1956. A nutrition-inhibition hypothesis of pathogenicity. Am. Nat. 90:183-194.

Honee, G., van den Ackerveken, G., van den Broek, H., Cozijnsen, T., Joosten, M., Lauge, R., Kooman-Gersmann, M., Vervoot, J., Vogelsang, R., Vossen, P., Wubben, J., and de Wit, P. 1994. Molecular characterisation of the interaction between the fungal pathogen Cladosporium fulvum and tomato. Euphytica 79:219-225.

Hwang, C.-S., and Kolattukudy, P. E. 1995. Isolation and characterization of genes expressed uniquely during appressorium formation by Colletotrichum gloeosporioides conidia induced by the host surface wax. Mol. Gen. Genet. 247:282-294.

Justesen, A., Somerville, S., Christiansen, S., and Giese, H. 1996. Isolation and characterization of two novel genes expressed in germinating conidia of the obligate biotroph Erysiphe graminis f.sp. hordei. Gene 170:131-135.

Keitt, G. W., and Boone, D. M. 1954. Induction and inheritance of mutant characters in Venturia inaequalis in relation to its pathogenicity. Phytopathology 44:362-370.

Larson, T., and Nuss, D. 1994. Altered transcriptional response to nutri- ent availability in hypovirus-infected chestnut blight fungus. EMBO J. 13:5616-5623.

Larson, T. G., Choi, G. H., and Nuss, D. L. 1992. Regulatory pathways governing modulation of fungal gene expression by a virulenceattenuating mycovirus. EMBO J. 11:4539-4548.

Lau, G., and Hamer, J. E. 1996. Regulatory genes controlling MPG1 expression and pathogenicity in the rice blast fungus Magnaporthe grisea. Plant Cell 8:771-781.

Lewis, R. 1953. An outline of the balance hypothesis of parasitism. Am. Nat. 87:273-279.

Logemann, J., Schell, J., and Willmitzer, L. 1987. Improved method for the isolation of RNA from plant tissues. Anal. Biochem. 163:16-20.

Marmeisse, R., van den Ackerveken, G., Goosen, T., de Wit, P., and van den Broek, H. 1994. The in-planta-induced ecp 2 gene of the tomato pathogen Cladosporium fulvum is not essential for pathogenicity. Curr. Genet. 26:245-250.

Marmeisse, R., van den Ackerveken, G. F. J. M., Goosen, T., de Wit, P. J. G. M., and van den Broek, H. W. J. 1993. Disruption of the avirulence gene avr9 in two races of the tomato pathogen Cladosporium fulvum cause virulence on tomato genotypes with the complementary resistance gene $C f 9$. Mol. Plant-Microbe Interact. 6:412-417.

Marzluf, G. 1997. Genetic regulation of nitrogen metabolism in the fungi. Microbiol. Mol. Biol. Rev. 61:17-32.

Oliver, R., and Osbourn, A. 1995. Molecular dissection of fungal phytopathogenicity. Microbiology 141:1-9.

Pieterse, C. M. J., Derksen, A. M. C. E., and Govers, F. 1994a. Expression of the Phytophthora infestans ipiB and ipiO genes in planta and in vitro. Mol. Gen. Genet. 244:269-277.

Pieterse, C. M. J., Riach, M. B. R., Bleker, T., Van den Berg-Velthuis, G. C. M., and Govers, F. 1993a. Isolation of putative pathogenicity genes of the potato late blight fungus Phytophthora infestans by differential screening of a genomic library. Physiol. Mol. Plant Pathol. 43:69-79.

Pieterse, C. M. J., Risseuw, E., and Davidse, L. 1991. An in plantainduced gene from Phytophthora infestans codes for ubiquitin. Plant Mol. Biol. 17:799-811.

Pieterse, C. M. J., Vanwest, P., Verbakel, H., Brasse, P., Van den BergVelthuis, G., and Govers, F. 1994b. Structure and genomic organization of the ipiB and ipiO gene clusters of Phytophthora infestans. Gene 138:67-77.

Pieterse, C. M. J., Verbakel, H. M., Spaans, J. H., Davidse, L. C., and Govers, F. 1993b. Increased expression of the calmodulin gene of the late blight fungus Phytophthora infestans during pathogenesis on potato. Mol. Plant-Microbe Interact. 6:164-172.

Puhalla, J. E., and Anagnostakis, S. L. 1971. Genetics and nutritional requirements of Endothia parasitica. Phytopathology 61:169-173.

Straney, D. C., and VanEtten, H. D. 1994. Characterization of the PDA1 promoter of Nectria haematococca and identification of a region that binds a pisatin-responsive DNA-binding factor. Mol. Plant-Microbe Interact. 7:256-266.

Talbot, N. J., Ebbole, D. J., and Hamer, J. E. 1993. Identification and characterisation of MPG1, a gene involved in pathogenicity from the rice blast fungus Magnaporthe grisea. Plant Cell 5:1575-1590.

van den Ackerveken, G., Dunn, R., Cozijnsen, A., Vossen, J., van den Broek, H., and de Wit, P. 1994. Nitrogen limitation induces expression of the avirulence gene avr9 in the tomato pathogen Cladosporium fulvum. Mol. Gen. Genet. 243:277-285.

VanEtten, H., Soby, S., Wasmann, C., and McCluskey, K. 1995. Pathogenicity genes in fungi. Pages 163-170 in: Pathogenicity Genes in Fungi. M. Daniels, J. Downie, and A. Osbourn, eds. Kluwer Academic Publishers, Dordrecht, The Netherlands. 